\title{
Evaluation of Solar Photosensitised River Water Treatment in the Caribbean
}

\author{
K. Tota-Maharaj ${ }^{1,2}$ and D. E. Meeroff ${ }^{3}$ \\ ${ }^{1}$ Hydrosystems Engineering Research Group, Department of Utilities Engineering, The University of Trinidad and Tobago, \\ Point Lisas Campus, Esperanza Road, Brechin Castle, Trinidad and Tobago \\ ${ }^{2}$ Urban Water Technology Centre, School of Science, Technology and Engineering, The University of Abertay Dundee, \\ Kydd Building, Bell Street, Dundee DD1 1HG, UK \\ ${ }^{3}$ College of Engineering and Computer Science, Department of Civil, Environmental and Geomatics Engineering, \\ Florida Atlantic University, 777 Glades Road, EE308, Boca Raton, FL 33431, USA
}

Correspondence should be addressed to K. Tota-Maharaj; kiran.tota-maharaj@utt.edu.tt

Received 6 June 2013; Revised 9 October 2013; Accepted 24 October 2013

Academic Editor: Hongtao Yu

Copyright (C) 2013 K. Tota-Maharaj and D. E. Meeroff. This is an open access article distributed under the Creative Commons Attribution License, which permits unrestricted use, distribution, and reproduction in any medium, provided the original work is properly cited.

\begin{abstract}
An economical supply of hygienic potable water is one of the most pressing public health issues facing developing countries in the Caribbean region today. This project investigates the performance of a novel solar photochemical reactor for disinfecting river water. The prototype photochemical reactor was designed, constructed, and tested for the microbiological degradation of faecal coliform present in River Water. The experiments evaluated the efficacy of two photosensitive dyes (malachite green and methylene blue) as agents for detoxification with concentrations ranging from 0.5 to $3.0 \mathrm{mg} / \mathrm{L}$. The photochemical reactor operated in a single-pass mode and compared the disinfection rates with direct photolysis. The photosensitizers showed a high efficacy rate using natural sunlight with microbial reduction ranging from 97 to $99 \%$ for concentrations as low as $0.5 \mathrm{mg} / \mathrm{L}$ of dye. The sensitizers were found to be photobleaching and were very effective at lower concentrations $(<2.0 \mathrm{mg} / \mathrm{L})$. Direct photolysis inactivation rate constants were 0.034 and $0.046 \mathrm{~min}^{-1}$, whilst degradation rates using methylene blue ranged from 0.057 to $0.088 \mathrm{~min}^{-1}$ and for malachite green from 0.057 to $0.086 \mathrm{~min}^{-1}$, respectively. One-way ANOVA was tested between the inflow and outflow pH, as well as the degradation rates constants for both photosensitisers with $P>0.01$. Post-solar disinfection included the use of a coconut fiber filter which polished the water removing residual dye concentrations and bacterial contaminants.
\end{abstract}

\section{Introduction}

With rapid industrialisation occurring in many Caribbean nations such as Trinidad and Tobago, a significant portion of the available sources of drinking water are chemically contaminated with industrial discharges, urban and agricultural runoff, and other sources of pollution Figure 1. The problem stems from a combination of leakage from sewerage lines and urban storm water runoff, which leads to contamination of municipal drinking water supplies by both microbiological and chemical contaminants. The availability of ample, safe, potable water may indeed prove to be one of the most critical problems for many developing countries in the region. Throughout the developing world, shortage of community water supplies, their actual or potential pollution from anthropogenic sources, inadequate treatment, and the resultant spread of associated diseases are still unresolved problems such as Cholera outbreaks. In addressing these issues, implementation of feasible water treatment measures is needed. An inexpensive supply of clean water is one of the most pressing public health issues such that there is a need to develop locally solutions for sustainable water treatment. Solar energy offers a renewable and sustainable potential source to meet these needs [1].

However, the use of natural light (sunlight) for water treatment (particularly disinfection) is not a recent innovation. The capture and storage of solar energy by photosensitised processes have been an active area of research 


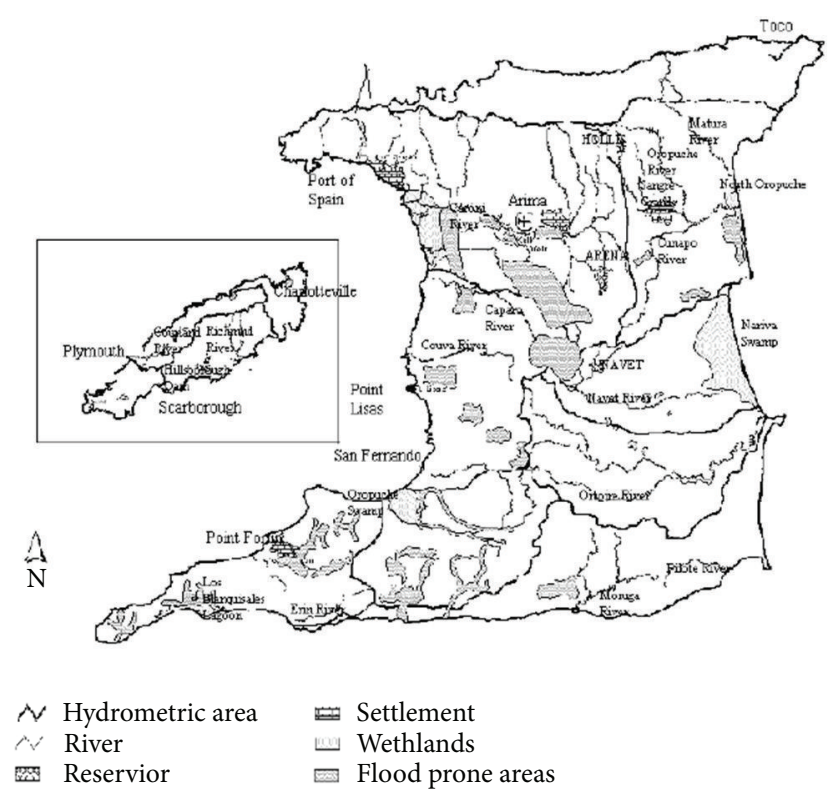

FIGURE 1: Water Regions (rivers, reservoirs, wetlands and hydrometric areas) in Trinidad and Tobago where solar photochemical reactors can be applicable [courtesy Key North Engineering Ltd].

for many years [2, 3]. Solar based water treatments have changed significantly over the years. Solar radiation and solar photochemical technologies are becoming increasingly appreciated over the years on its influence of organic pollution degradation and applicability for water and wastewater treatment [4-7].

Solar UV radiation is a perpetual source of natural energy that along with other forms of renewable energy has great potential for a wide variety of applications because it is abundant and accessible. Solar radiation and its associated technologies are rapidly gaining ground as a supplement to nonrenewable sources of energy, which have a finite supply. The use of solar technologies is still very much underexploited in Trinidad and Tobago when compared to the amount of solar energy available and its geographical location ( $11^{\circ} \mathrm{N}$ latitude); there is an average solar incidence of approximately 3000 hours/year on Trinidad and Tobago [8].

\section{Background of Research}

Solar photochemical technologies can provide the water utility companies throughout Trinidad, Tobago, and the rest of the Caribbean with a sustainable tool for the detoxification of water and wastewater with clean energy from the sun. The purpose of this research is to assess solar photochemical technologies for microbial disinfection of potable water supplies in Trinidad and Tobago. The characteristics and performance criteria will be based on the solar photosensitisation processes and its effectiveness in reducing water borne infectious bacteria such as faecal coliforms. The paper investigates the performance of a solar photochemical reactor to disinfect water using direct photolysis (solar UV radiation only) and photodynamic inactivation via two exogenous photosensitisers (methylene blue and malachite green).

\section{Mechanisms of Photosensitisers}

Photochemical reactions induced by natural light have been known for some time, but much of this field remains obscure [9-11]. Many inorganic and organic chemical pollutants typically found in natural surface waters are capable of absorbing energy with consequent chemical changes. These substances are referred to as photoreactive chromophores and participate in direct photolysis reactions $[12,13]$.

Natural light plays a primary role in the photodecomposition of pollutants $[14,15]$. Other important mechanisms include indirect photolysis, photosensitisers, and photocatalysis. When exposed to light of the appropriate wavelength, photosensitisers generates a reactive species, such as a hydroxyl radical or peroxy radical, which can subsequently react with the contaminant species $[16,17]$. The concept of photodynamic inactivation or photosensitisation of microorganisms evolved from experiments conducted in the early 19th century as sensitized photooxidation treatment used for the destruction of bacteria and viruses present in water $[12,14]$. These studies reported the inactivation of viruses present in wastewater by visible light in the presence of an exogenous photosensitizing dye (acridine) $[2,3]$. Photosensitisers absorb light and are photochemically excited to a higher energy state. This treatment process offers an advantage over the photocatalytic process because photosensitisers absorb light in the visible spectrum, allowing usage of a greater percentage of available sunlight $[3,12]$. There are two types of photosensitizing compounds, exogenous and endogenous; exogenous compounds react with light directly, whereas endogenous compounds chemically convert the contaminants into photoreactive compounds. Exogenous compounds include fluorescent substances or dyes such as eosin, methylene blue, rose bengal, benzopyrene, and malachite green $[16,17]$. Endogenous compounds include porphyrins, cytochromes, cytochrome oxidase, amino acids, flavins, and chlorophylls.

3.1. Photosensitisation Reactions. Photosensitisation is a process in which reactions to normally ineffective radiation doses are induced in a system by the introduction of a specific radiation-absorbing substance (the photosensitiser) which causes another substance (the substrate) to be changed by radiation [12]. When used to describe the reaction of bacteria to an exogenous chemical and UV or visible radiation, the term includes both phototoxic and photodynamic reactions $[12,13]$. The reaction proceeds via the triplet excited state, owing to its longer lifetime relative to the singlet excited state:

$$
\begin{aligned}
{ }^{1} \gamma+h v & \longrightarrow(\text { Excited singlet state }) \\
& \longrightarrow{ }^{3} \gamma(\text { Excited triplet state })
\end{aligned}
$$

The excited sensitizer then transfers some of its excess energy to an acceptor, forming an intermediate reactive species, such as singlet oxygen, ${ }^{1} \mathrm{O}_{2}$, peroxyl radical $\left({ }^{\circ} \mathrm{OOH}\right)$, 
hydroperoxyl radical $\left(\mathrm{HO}^{2-}\right)$, hydroxyl radical $\mathrm{OH}^{-}$, or other free radicals. Acceptors can be either organic material or dissolved inorganic species produced from the reaction of the triplet sensitizer with organic material subsequently reacts with atmospheric oxygen under aerobic conditions:

$$
\begin{aligned}
{ }^{3} \gamma+\mathrm{OM} & \longrightarrow \text { (Transient species })+\mathrm{O}_{2} \\
& \longrightarrow \text { Oxidation products }+\gamma
\end{aligned}
$$

When the photochemical $\gamma$ transfers its excess energy to molecular oxygen instead of $\mathrm{OM}$, the oxygen molecule changes from its ground electronic state, the triplet state $\left({ }^{3} \sum_{\mathrm{g}} \mathrm{O}_{2}\right)$, to the excited singlet state, ${ }^{1} \mathrm{O}_{2}$, to form oxidation products described by the mechanism $[12,13]$ :

$$
\begin{gathered}
{ }^{3} \gamma+{ }_{\mathrm{g}} \sum_{\mathrm{g}} \mathrm{O}_{2} \longrightarrow \gamma+{ }^{1} \mathrm{O}_{2} \\
{ }^{1} \mathrm{O}_{2}+\mathrm{OM} \longrightarrow \text { Oxidation products }
\end{gathered}
$$

The wavelength of light absorption is specific for each photosensitiser. For instance, malachite green, rose bengal and methylene blue absorb in solar UV-A region wavelength at $\lambda \max =380 \mathrm{~nm}$. Photosensitisers applicable for water and wastewater treatment should possess the following characteristics $[11,18,19]$ :

(i) capability to induce reactions with solar energy,

(ii) chemical stability during radiation or degrade to a sensitizing species,

(iii) nontoxic and do not degrade to a toxic species upon photoactivation,

(iv) free of reactive functional groups,

(v) good light absorption capacity,

(vi) solubility in water yet easy to remove from the aqueous phase.

Methylene blue is already used on a technical scale for the disinfection of domestic wastewater $[13,20]$. It is incompatible with strong oxidising and reducing agents. Disinfection of water with photosensitisers such as methylene blue generates reactive oxygen species in the presence of light and oxygen. It has been found that the chemiexcited photosensitisers such as methylene blue could produce photodynamic damage on water-borne viruses [12]. Photodynamic virus inactivation with methylene blue and light at low concentrations has been effectively proven by Huang et al. [21]. Methylene blue was selected as a photosensitizing agent, with the dengue virus as a model virus. The studies by Huang et al. [21] found that the dengue virus was completely inactivated in 5 minutes when subjected to $<1.0 \mathrm{mg} / \mathrm{mL}$ of methylene blue.

Another important photosensitiser is malachite green, which has powerful antifungal properties and is used in prophylactic treatment in Trinidad and Tobago's aquaculture industry. Historically, malachite green has been used effectively against a range of marine parasites such as Gyrodactylus, Dactylogyrus, Ichthyobodo, and Chilodonella which are all common infections with marine life [14, 22, 23]. The relatively long active life of this treatment together with the low filter toxicity makes it ideal for tackling the complex life cycle of this protozoan parasite $[5,24]$. The selected photosensitisers presumably react as triplets and through the generation of singlet oxygen acts as the main photodegradation mechanism due to the $\mathrm{OH}$ radical and electron transfer reactions. Souza et al. [25] compared the photodynamic fungicidal efficacy of methylene blue and malachite green. The study found that both photosensitisers for the antimicrobial photodynamic inactivation against Candida albicans were effective in reducing initial concentrations of Candida albicans $10^{6} \mathrm{CFU} / \mathrm{mL}$ by 99.99\%.

\section{Experimental Methodologies}

The photochemical reactor design was a non-concentrating fixed bed tubular reactor (Figures 2 and 3). It does not concentrate solar radiation; therefore, the efficiency is not affected by factors associated with concentration and solar tracking. The reactor consisted of serpentine shaped tubing and was constructed with borosilicate glass (pyrex glass), supported by an aluminium metal frame as the reflector. Borosilicate glass was chosen for three reasons: (i) it is an efficient transmitter of solar radiation at wavelengths longer than $240 \mathrm{~nm}$, (ii) it is available locally in Trinidad, and (iii) it is sufficiently durable to the weathering effects of sunlight and scratches. The choice of a tubular photoreactor has a decided advantage because of the inherent structural efficiency of tubing.

The angle of inclination was set at $12^{\circ}$ to approximate the latitude of Trinidad $\left(11^{\circ} \mathrm{N}\right)$ for optimum solar irradiation. This orientation of the solar reactor and its set inclination angle from the horizontal provide the necessary conditions for maximum influx of solar radiation [8]. The selected configuration for the photoreactor regarding the angle of tilt was set to the angle of latitude for Trinidad to maximise annual solar energy onto the reactor's surface [10]. Other angles of inclination could prove just as effective because of the rounded shape of the tubes. The dimensions of the glass tubing were as follows: total length $=12 \mathrm{~m}$; outer diameter $=$ $19 \mathrm{~mm}$; wall thickness $=1 \mathrm{~mm}$; volumetric capacity $=5$ litres. The unit also prevented air-gap formation by inducing an upward flow of floating bubbles.

All piping used to connect to the photoreaction zone was made of transparent polyvinylidene fluoride (PVDF) polymer tubing. This material was selected because it is resistant to corrosion and is inert to degradation by UV solar radiation. PVDF is also strong enough to withstand varying pressure drops across the system. The raw water tank was constructed as a plastic insulated tank, insulated with fiberglass, $76 \mathrm{~mm}$ thick around the plastic tank. The fiberglass has a thermal conductivity value of $0.050 \mathrm{~W} / \mathrm{mK}$. Aluminium sheeting was used around the entire tank as a radiation shield. These modifications were made to the raw water tank, so that the bacteria and microbial pollutants to be tested through the photochemical reactor were not affected by thermal changes or solar radiation in the intake reservoir. A water level gauge was set at a fixed height using transparent glass tubes in order 


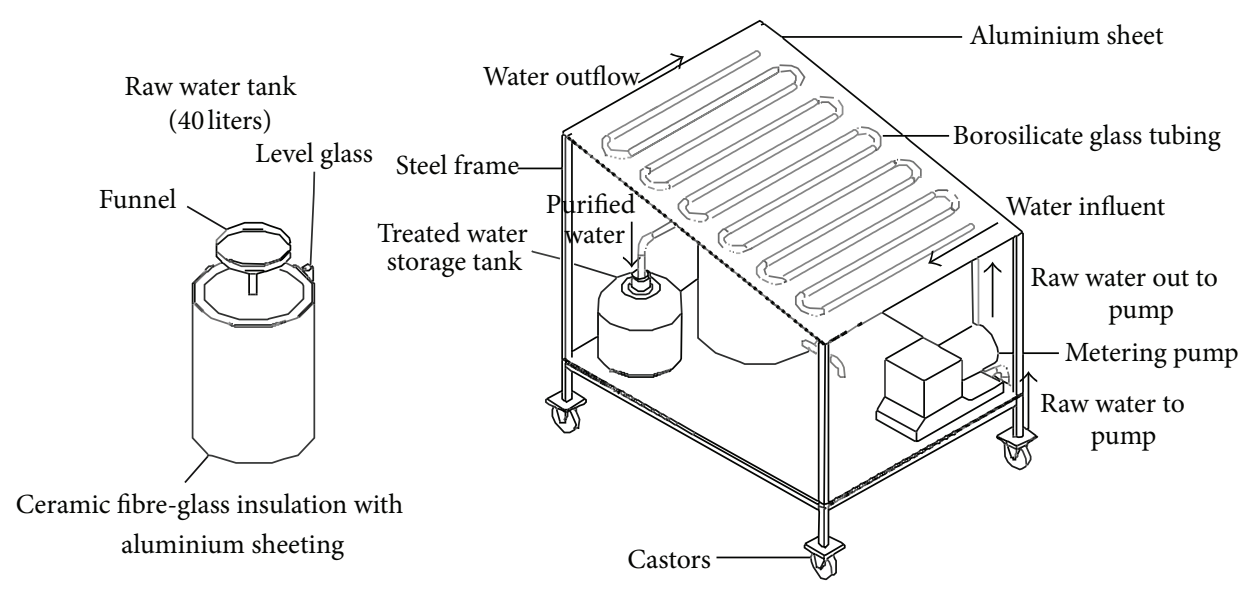

FIGURE 2: Schematic of non-concentrating, inclined flat-fixed bed solar photochemical reactor.

to read the level of raw water and water to be treated when it approaches 40 litres.

A Pulsafeeder PULSAtron Series E electronic metering pump (Quantrol Inc, Napierbille, IL, USA) was selected to control the flow rate through the photochemical reactor. Flow rates could be varied from a minimum of 2 litres/hour to a maximum of 40 litres/hour. The flow rates did not exceed 25 litres/hour throughout the experiments. A digital radiometer or solarmeter (Solartech Ltd USA, model SM5.0) was used to measure the intensity of solar UV-A radiation onto the surface of the photochemical reactor. A ColeParmer infrared thermometer was used to measure inflow and outflow temperatures with a range from $0^{\circ}$ to $750^{\circ} \mathrm{F}$ (from $-18^{\circ}$ to $399^{\circ} \mathrm{C}$ ). The thermometer displayed minimum, maximum, differential temperature, and average temperatures in ${ }^{\circ} \mathrm{F}$ or ${ }^{\circ} \mathrm{C}$. A Tecpel pH meter (Fischer Scientific, Tampa, FL, USA) was used with a $\mathrm{pH}$ resolution of 0.01 and $+/-0.02$ accuracy.

The photoreactor is capable of being operated in a single-pass mode or batch mode. The solar insolation varied throughout the day and, hence, the flow ranges were adjusted as necessary to compensate for the fluctuation in solar energy weekly. For this research project, the photoreactor unit was operated in single-pass mode to measure the decay of the microbial pollutants at specific flow rates.

River water from upstream and downstream the MaracasSt. Joseph River was used for the solar photochemical disinfection and treatment processes. The Maracas-Saint Joseph valley is a largely urbanised area on the Northern Range Mountains in Trinidad, West Indies. One of the major roads running through the valley (The Maracas Royal Road) drains into the Maracas-St. Joseph River which is a major tributary to the largest river in the country (Caroni River). Water sampling occurred on twice weekly and was found that similar bacterial populations of total coliforms (ranged from 230 to 5000 existed at both sampling locations shown in Figures 4. Varied dosages of the photosensitisers malachite green and methylene blue were applied, ranging from 0.5 to $3.0 \mathrm{mg} / \mathrm{L}$, respectively. The average operational daily time of exposure for the river water within the photoreactor was

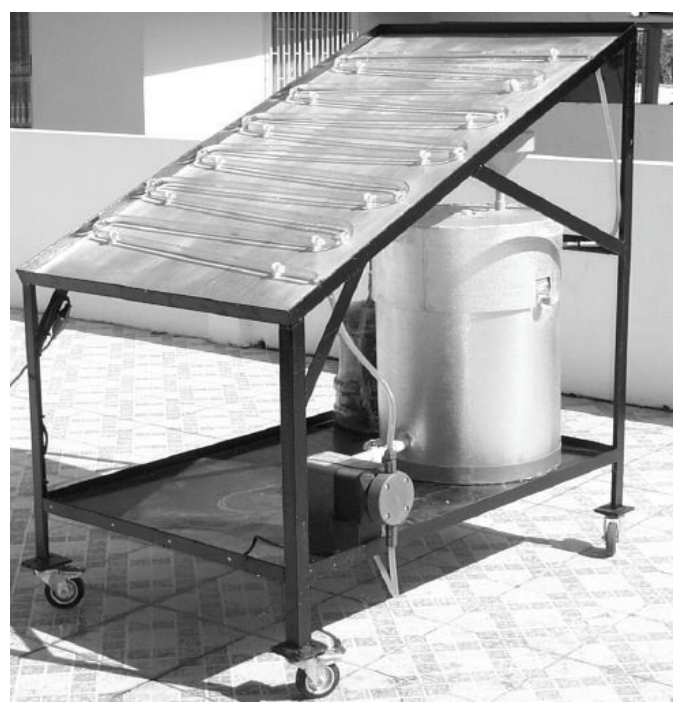

FIGURE 3: Photograph of solar photochemical reactor installed and in operation, North-East, Trinidad, West Indies.

approximately 10 hours whereby analysis occurred every 2 hours with new batches of influent river water placed into the raw water tank (Figure 2). The experimental tests were carried out in the photoreactor under similar conditions of $\mathrm{pH}$, initial concentrations of the photochemicals and dosage; and exposure time to solar radiation.

4.1. Microbiological Procedure. Bacterial characteristics for faecal coliforms present in the river water varied throughout analysis for the variable concentrations of photochemical dyes. The biocidal efficacies of the photosensitisers were evaluated in this project using faecal coliforms as the indicator organisms. The membrane filter (MF) technique was used to enumerate faecal coliforms as follows [26, 27].

(a) Filtration of Sample. A $0.45 \mu \mathrm{m}$ membrane filter (Fischer Scientific, Tampa, FL, USA) was used to filter the sample 


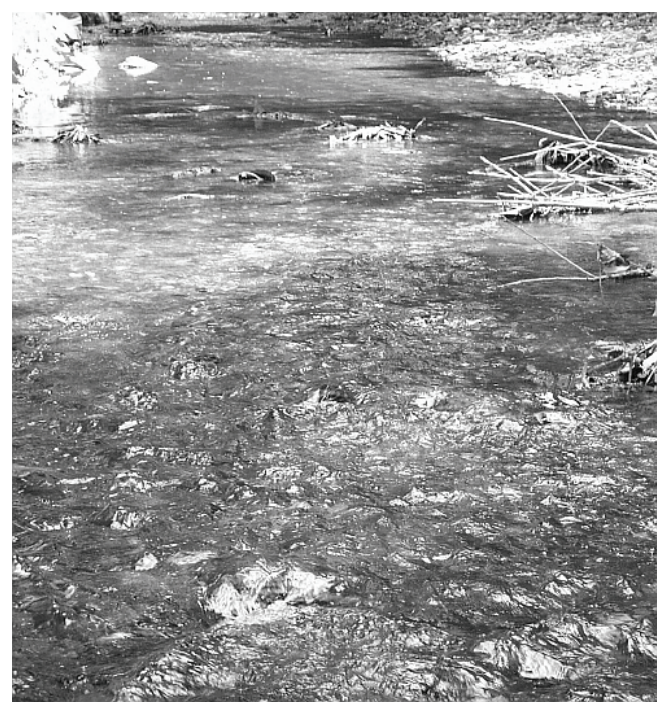

(a)

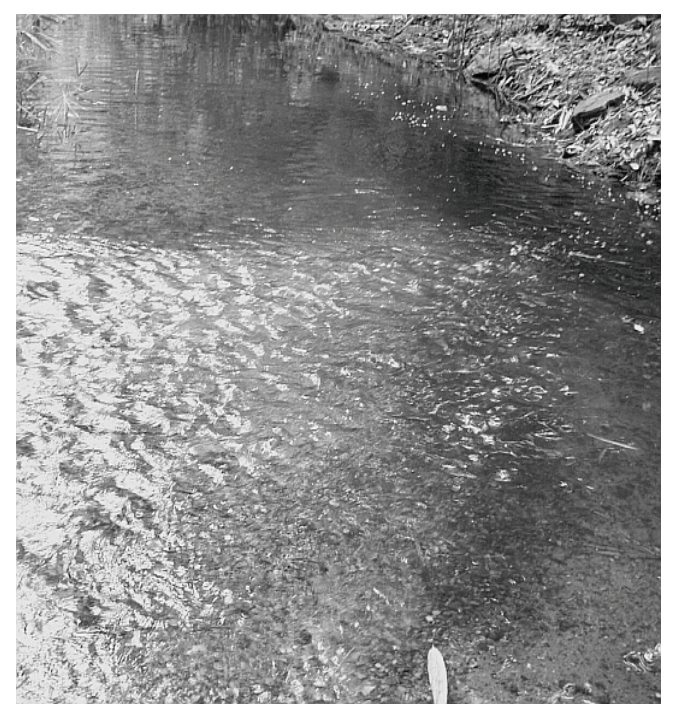

(b)

Figure 4: (a) Maracas-St. Joseph River downstream sample site and (b) upstream sample site.

in plastic filter funnels in establishing the faecal coliform density.

(b) Preparation of Culture Dish. A sterile absorbent pad was placed in each culture petri dish and approximately $2 \mathrm{~mL}$ of M-FC medium was used to saturate the pad. The prepared filter was placed on the medium pad.

(c) Incubation. Prepared cultures were placed in sealed petri dishes, submerged in a water bath, and incubated for $24( \pm)$ 1 hour at $44.5( \pm) 0.2^{\circ} \mathrm{C}$. All prepared cultures were placed in the water bath within 30 minutes after filtration.

(d) Counting. The colonies produced by faecal coliform bacteria on M-FC medium were various shades of blue. Pale yellow colonies indicated the presence of typical E. coli. Nonfaecal coliform colonies were identified by their grey to cream colour. Positive colonies were then counted under a microscope.

4.2. Solar Photochemical Kinetics of Disinfection. Inactivation of microorganisms is a gradual process that involves a series of physical, chemical, and biological changes. In an effort to predict the outcome of water and wastewater disinfection, various models have been developed on the basis of experimental data. The principal disinfection theory used today is the Chick-Watson model [28-30] which expresses the rate of inactivation of microorganism by a first order differential equation.

$$
\begin{gathered}
\ln \frac{N}{N_{o}}=-k i T, \\
\frac{N}{N_{o}}=e^{-k i T},
\end{gathered}
$$

where $N$ is the bacterial density after exposure in colonyforming units (CFU) per milliliter of effluent, $N_{o}$ is the initial bacteria density exposure $(\mathrm{CFU} / \mathrm{mL}), N / N_{o}$ is the bacterial survival ratio, $k$ is the inactivation rate constant $\left(\mathrm{cm}^{2} / \mu \mathrm{W} \mathrm{min}\right), i$ is the intensity of received solar $\mathrm{UV}-\mathrm{A}$ radiation $\left(\mu \mathrm{W} / \mathrm{cm}^{2}\right), T$ is the time of exposure to solar $\mathrm{UV}$ A radiation (in minutes), and $e=2.7182$. Units for $i, T$, and $k$ may be substituted with Watts $/ \mathrm{m}^{2}$, hours, and $\mathrm{m}^{2} / \mathrm{Wh}$, respectively. Exposure time $T$ corresponds to the residence time of the water as it flows through from the inlet to the outlet port of the solar photochemical reactor. It is calculated by

$$
T=\frac{V}{Q},
$$

where $V$ is the total capacity of the reactor transparent tubing (litres) and $Q$ is the flow rate of water passing through the reactor (litres per $\mathrm{min}$ ).

\section{Results and Discussion}

As solar intensity increases, exposure time has to be decreased proportionally to keep the product of time and intensity or fluence constant. For the flow through system, this was controlled by regulating the rate of flow with the variable pump. Table 1 presents the mean temperature variation between influent and effluent of the photoreactor, average flow rates, $\mathrm{pH}$, solar UV intensities, and influent faecal coliform bacterial population.

The flow rates allowed a temperature variation of approximately $5^{\circ} \mathrm{C}$ between the inflow and outflow water. The solar UV intensities ranged from 34 to $56 \mathrm{~W} / \mathrm{m}^{2}$ with lower intensities linked to higher cloud cover and generally the rainy season (July to December). For the Maracas-St. Joseph River, the faecal coliform concentrations ranged from 310 
TABLE 1: Mean water temperatures $\left({ }^{\circ} \mathrm{C}\right), \mathrm{pH}$, flow rates (litres/hour), daily sunlight exposure time (hours), solar intensity $\left(\mathrm{W} / \mathrm{m}^{2}\right)$, and influent microbial pollutant concentration (CFU/mL) from June 2008 to May 2010. Average daily operational time was 9.5 hours.

\begin{tabular}{|c|c|c|c|c|c|c|c|}
\hline \multirow{2}{*}{$\begin{array}{l}\text { Month } \\
\text { (June-May) }\end{array}$} & \multicolumn{2}{|c|}{ Water temperature $\left({ }^{\circ} \mathrm{C}\right)$} & \multicolumn{2}{|c|}{$\mathrm{pH}$} & \multirow{2}{*}{$\begin{array}{l}\text { Flow rate } \\
\text { (litres/hr) }\end{array}$} & \multirow{2}{*}{$\begin{array}{l}\text { Intensity } \\
\left(\mathrm{W} / \mathrm{m}^{2}\right)\end{array}$} & \multirow{2}{*}{$\begin{array}{l}\text { Influent faecal coliform } \\
(\mathrm{CFU} / \mathrm{mL})\end{array}$} \\
\hline & Inflow & Outflow & Inflow & Outflow & & & \\
\hline 1 & 27.7 & 29.8 & 7.31 & 7.32 & 18.2 & 41 & 805 \\
\hline 2 & 28.8 & 30.5 & 7.30 & 7.33 & 19.5 & 43 & 415 \\
\hline 3 & 34.5 & 36.2 & 7.24 & 7.42 & 17.1 & 48 & 1595 \\
\hline 4 & 36.0 & 38.4 & 7.37 & 7.49 & 20.5 & 56 & 1145 \\
\hline 5 & 35.1 & 37.8 & 7.37 & 7.36 & 18.3 & 55 & 1380 \\
\hline 6 & 36.3 & 38.5 & 7.61 & 7.70 & 22.8 & 46 & 2200 \\
\hline 7 & 36.4 & 41.3 & 7.86 & 7.82 & 16.7 & 54 & 725 \\
\hline 8 & 32.3 & 35.3 & 7.85 & 7.90 & 24.0 & 55 & 585 \\
\hline 9 & 31.0 & 36.7 & 7.87 & 7.83 & 19.6 & 42 & 1595 \\
\hline 10 & 33.8 & 37.4 & 7.70 & 7.75 & 22.3 & 46 & 2250 \\
\hline 11 & 32.5 & 38.8 & 7.64 & 7.71 & 22.7 & 48 & 3470 \\
\hline 12 & 33.9 & 35.2 & 7.40 & 7.43 & 21.4 & 54 & 3940 \\
\hline 13 & 34.8 & 36.7 & 7.47 & 7.44 & 19.1 & 55 & 4665 \\
\hline 14 & 32.1 & 35.3 & 7.40 & 7.44 & 22.8 & 39 & 3185 \\
\hline 15 & 26 & 33.8 & 7.36 & 7.43 & 17.7 & 41 & 2070 \\
\hline 16 & 27.5 & 30.0 & 7.31 & 7.35 & 18.6 & 47 & 1030 \\
\hline 17 & 26.4 & 28.7 & 7.27 & 7.31 & 18.2 & 43 & 695 \\
\hline 18 & 27.5 & 28.4 & 7.26 & 7.24 & 21.8 & 45 & 310 \\
\hline 19 & 31.3 & 34.6 & 7.25 & 7.35 & 23.4 & 36 & 1475 \\
\hline 20 & 35.2 & 37.9 & 7.33 & 7.38 & 20.9 & 34 & 4095 \\
\hline 21 & 34.8 & 38.5 & 7.17 & 7.28 & 19.4 & 44 & 4830 \\
\hline 22 & 35.1 & 37.3 & 7.29 & 7.28 & 23.7 & 47 & 3330 \\
\hline 23 & 32.8 & 35.1 & 6.88 & 7.33 & 24.5 & 51 & 2200 \\
\hline 24 & 33.5 & 37.2 & 7.38 & 7.35 & 24.6 & 50 & 1145 \\
\hline
\end{tabular}

to $4830 \mathrm{CFU} / \mathrm{mL}$. As the higher values are thought to be caused by untreated stormwater runoff entering the water system, nearby domestic buildings may also be discharging untreated or partially treated wastewater directly into the river, in addition to animal sources. Controlled experiments were conducted placing water samples at room temperatures $\left(28^{\circ} \mathrm{C}\right)$ and dark conditions adding both photosensitisers with concentrations of 0.5 to $3.0 \mathrm{~m} / \mathrm{L}$. The water samples were tested after a 5 -hour period for decay rates. This resulted in very little and slow degradation $(<6 \%)$ of faecal coliforms.

One-way ANOVA was tested between the inflow and outflow $\mathrm{pH}$, with $P>0.01$ indicating no statistical differences for $\mathrm{pH}$. Thus neither photosensitisers altered the effluent $\mathrm{pH}$. The photochemical decay rates and other relevant values were computed by (5) representing the percentage of degradation of bacteria using mean values for the photodecomposition rate constant $k$ to minimise any bias introduced inadvertently. This equation is considered a good approximation for the assumed uniform flow (plug flow) of the water through the reactor [18].

The experimental data obtained the derived exponential equation with the degradation of bacteria " $y$ " expressed exponentially for direct photolysis (no photochemicals) and photosensitised disinfection as $y=100 e^{-k I T}$. Illustrated in
Figure 5, the photodegradation of the microbial pollutant faecal coliforms is a function of solar UV-A fluence. Based on measured data, the derived exponential equations for direct photolysis can be expressed as $y=100 e^{-0.034 I T}$. For the photosensitiser methylene blue concentrations ranging from 0.5 to $3.0 \mathrm{mg} / \mathrm{L}$, the following exponential equations describe the decontamination process with respect to solar influx, $y=100 e^{-0.057 I T}, y=100 e^{-0.068 I T}, y=100 e^{-0.079 I T}$, $y=100 e^{-0.051 I T}, y=100 e^{-0.072 I T}$, and $y=100 e^{-0.088 I T}$; respectively.

Figure 6 illustrates the photodegradation of faecal coliforms expressed in as a percentage with respect to the solar UV-A fluence. Once more, the experimental data obtained the derived exponential equations, with degradation of bacteria $y$, expressed exponentially for direct photolysis (no photochemicals) as $y=100 e^{-0.046 I T}$. For concentrations of malachite green ranging from 0.5 to $3.0 \mathrm{mg} / \mathrm{L}$, the degradation curves are described by $y=100 e^{-0.057 I T}$, $y=100 e^{-0.064 I T}, y=100 e^{-0.078 I T}, y=100 e^{-0.068 I T}$, $y=100 e^{-0.076 I T}$, and $y=100 e^{-0.086 I T}$, respectively. From the graphs plotted using mean experimental data and the derived exponential equation which represents the degradation of the pollutant as shown in Figures 5 and 6, it 
TABLE 2: Inactivation rate constants $\left(k, \mathrm{~min}^{-1}\right)$, for direct photolysis (solar radiation), and photosensitisers methylene blue and malachite green at varying concentrations of 0.5 to $3.0 \mathrm{mg} / \mathrm{L}$.

\begin{tabular}{lccc}
\hline Photochemical processes & \multicolumn{2}{c}{$\begin{array}{c}\text { Inactivation rate constants }\left(k, \mathrm{~min}^{-1}\right) \\
\text { Malachite green }\end{array}$} & $\begin{array}{c}\text { Photochemical dosage }(\mathrm{mg} / \mathrm{L}) \\
\text { Methylene blue }\end{array}$ \\
\hline Direct photolysis & 0.034 & 0.046 & - \\
\hline & 0.057 & 0.057 & 0.5 \\
& 0.068 & 0.064 & 1.0 \\
Photosenstiser & 0.079 & 0.078 & 1.5 \\
& 0.051 & 0.068 & 2.0 \\
& 0.072 & 0.076 & 2.5 \\
\hline
\end{tabular}

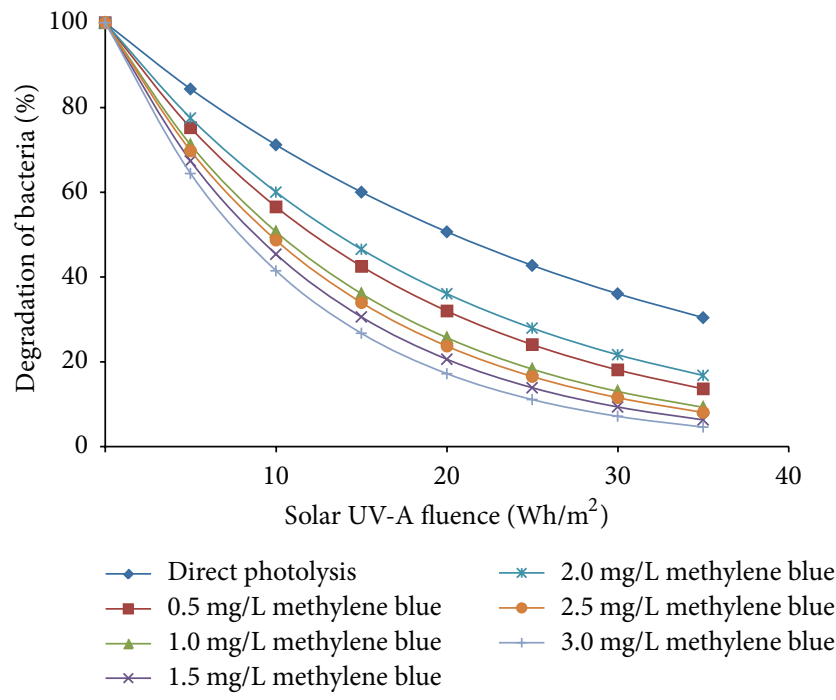

Figure 5: Photodegradation of faecal coliforms as a function of solar UV fluence, with direct photolysis and photosensitiser methylene blue applied.

can be seen that an increase in photochemical concentrations for both methylene blue and malachite green amplifies the photodegradation rate of faecal coliform. The degradation rates increase linearly with the photosensitiser concentrations and the kinetics of the process is presumably controlled by the rate of the intermediating species generation that is responsible for the substrates photooxidation as presented in Table 2. The kinetics of the disappearance of both the bacteria and the photochemicals methylene blue and malachite green occurred at similar rates according to the Chick-Watson kinetic model [28-30].

The photosensitisers methylene blue and malachite green were effective because of their strong photooxidising properties and the minimal production of disinfectant's byproducts. The mechanisms of photochemical treatment of water in the presence of the photosensitisers occur by electron transfer reactions and hydroxyl radical $\left({ }^{\circ} \mathrm{OH}\right)$ generation. The radical species ( $\mathrm{OH}$ radical) causes the inactivation of faecal coliforms. Free hydroxyl radicals act as scavengers and are responsible for the modeled pollutant putrefaction. Both photosensitizers included molecules interacting with light

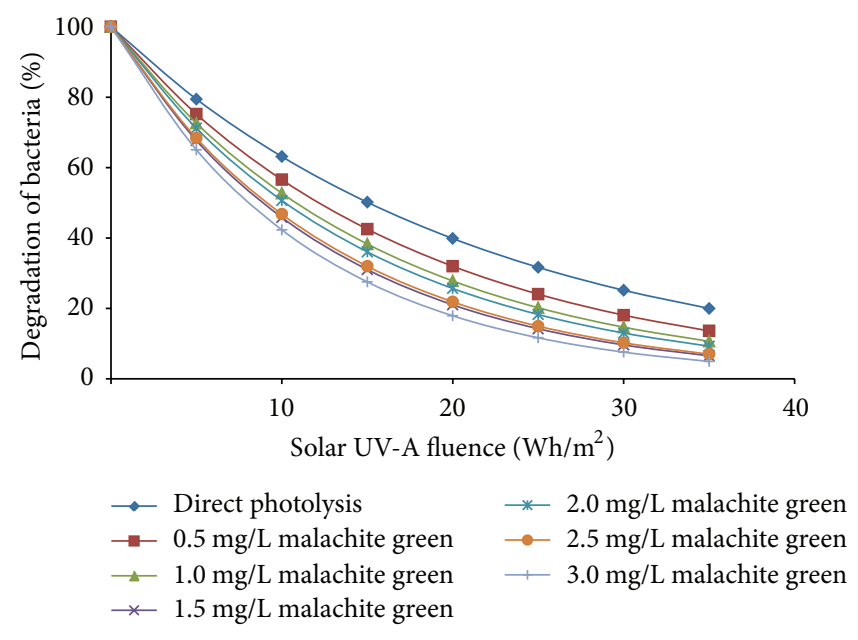

FIGURE 6: Photodegradation of microbial pollutant faecal coliforms as a function of solar UV fluence, with direct photolysis and photosensitiser malachite green applied.

and having their properties modified under solar irradiation. Their (malachite green and methylene blue) photochemical and photophysical characterization has a huge importance in the detoxification process for the bacteria. From (1) to (4), the high triplet state quantum yields and long triplet lifetimes as well as high singlet oxygen quantum yields were efficient for the photosensitization process. The antimicrobial properties and pollutant remediation as a result of the singlet oxygen was used to oxidize the pollutants into environmental safe derivatives. The negative characteristics of the bacterial membranes require cationic photosensitisers [31]. Their electrostatic interactions ensure maximized damages by the singlet oxygen and the cationic charges and amphiphilic structures optimize bacterial cell penetration. Methylene blue and malachite green basic structures are designed for optimized photosensitisers by the introduction of hydrophobic chains to enhance the amphiphilicity of highly hydrophilic molecules.

Almost all organic molecules reacts with $\left({ }^{\circ} \mathrm{OH}\right)$ and degrades. Homogenous methylene blue and malachite green have been shown to be highly effective for each concentration of the photosensitiser, altering the disintegration rates noticeably (Table 2). The decay curves for direct photolysis 


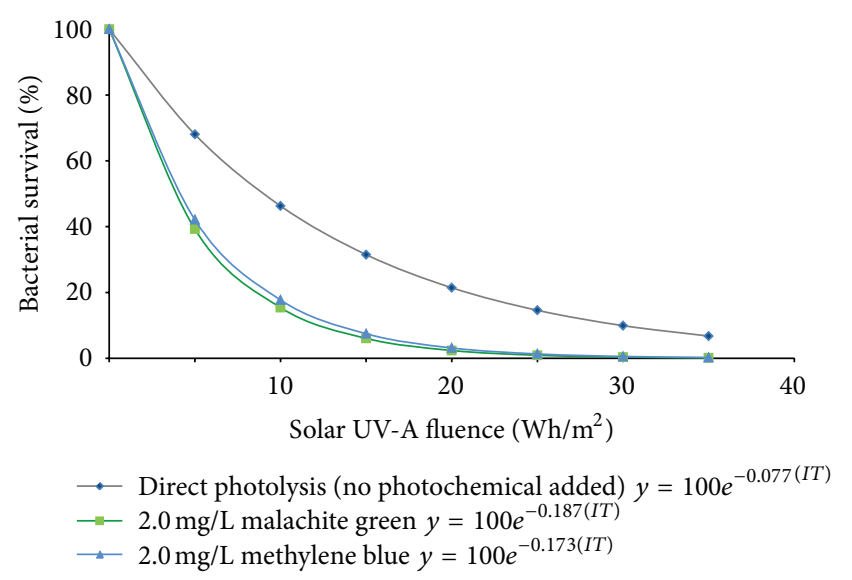

Figure 7: Comparison of bacterial (faecal coliforms) survival as a function of solar UV fluence with direct photolysis and photosensitisers malachite green and methylene blue at $2.0 \mathrm{mg} / \mathrm{L}$ concentration.

disinfection differ significantly to the decay curves with added photochemicals. At a concentration of $3.0 \mathrm{mg} / \mathrm{L}$ with either photosensitiser the fastest decompositions rates are observed; for higher concentrations $(>3.0 \mathrm{mg} / \mathrm{L}$ of photochemicals), the reactor's surface eventually became opaque and photochemical disinfection was limited. As a result of the rise in water temperatures between the inlet and outlet ports of the photoreactor not exceeding $10^{\circ} \mathrm{C}$ whilst experiments were run for 9 to 10 hour intervals, the influential photodecomposition effect can be considered as a result of solar radiation. The sensitizers are photobleaching which can be effective at lower concentrations $(<2.0 \mathrm{mg} / \mathrm{L})$ and can be applied at a fixed low dosing rate to the photochemical reactor.

The faecal coliform concentration detected in the natural waters on average was $2500 \mathrm{CFU} / \mathrm{mL}$. Figure 7 illustrated the environmental fate of the bacterial concentrations determined by direct photolysis and photosensitization via malachite green and methylene blue at a concentration of $2 \mathrm{mg} / \mathrm{L}$. It can be seen that the use of photosensitisers at this concentration accounted for the $15 \%$ difference in degradation rates for the natural river water. The steady-stage concentrations of singlet oxygen and the hydroxyl radical $\left({ }^{\circ} \mathrm{OH}\right)$ as described from (1) to (4) was the dominant degradation mechanism [32]. It appears that the direct reaction of singlet and triplet excited state with the faecal coliform accounted for the increased loss of the bacteria. Moreover, the pseudo-first-order photodegradation rate (5) showed an effective removal efficiency, which further supported the assumption that excited states of oxygen play a key role in the photochemical transformation of bacteria in natural waters. The photochemical processes lead to the production of new oxidizing chemical species (oxygen in the form of singlet, free radicals or reactive oxygen species), which is highly unstable and interacted with the closely surrounding molecules of the bacteria, thus damaging the cell molecular structures [33].

Furthermore after one-way ANOVA was tested between the degradation rate constants for both photosensitisers

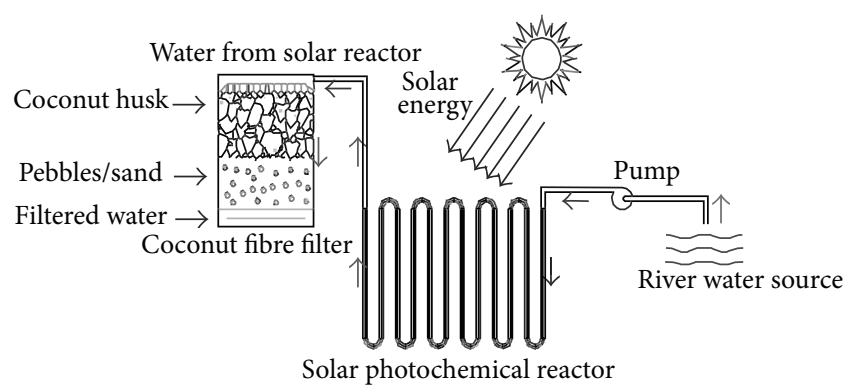

FIGURE 8: Post-solar photochemical disinfection treatment using coconut-husk fibres for photosensitized dye absorption and filtration.

$P>0.01$ indicating there were no significant differences. The effluent water was analysed for disinfection by-products (DBPs) from the photoinduced dyes and no halogenated DBPs were produced which is an additional benefit of the system. The transfer of electrons between the photosensitiser and the substrate (faecal coliform bacteria) results in the creation of products that have an uneven number of electrons. Such radical species are often highly reactive. Radicals can further react with additional biological substrates producing changes in structure and/or function. Superoxide and hydroxyl radicals are important radical species that are often produced by photoinduced reactions in biological environments. Malachite Green is marketed as a photosensitiser that produced biological effects via hydroxyl radicals. This type of photochemical reaction requires direct interaction between the photosensitiser and the substrate and favours low oxygen concentrations, since oxygen competes with the substrate for interaction with the photosensitiser. The second reaction occurs as a result of the transfer of energy from the photosensitiser to oxygen producing excited singlet state oxygen. Typically photosensitisers like methylene blue absorb light and are converted to a different singlet state with higher energy content.

Rural water systems in developing countries like Trinidad and Tobago require high capital depending upon the extent and quality of water and wastewater services provided. The high costs of conventional systems do not permit capital payback by residents in lower income regions of the twin-island republic. Thus, in an effort to reduce overall system cost; a cheaper coconut-husk filter was incorporated to aid in the water purification process and overall treatment efficiency. This further post-solar photochemical disinfection treatment was conducted as illustrated in Figure 8. The additions to the experiment included the use of coconut-husk fibre as a filtration medium which acted as an adsorbent for efficient dye removal. Coconut-husk fibres are readily available as a free waste product across Trinidad and Tobago in addition to the use of sand and pebbles from the St. Joseph River. The post-filtration system acted as a polishing stage for the water removing/absorbing the full concentrations of the dyes in addition to straining the remaining concentrations of the faecal coliform bacteria. The filter consisted of shredded coconut husk which filtered out suspended solids and dye 
concentrations acting as a "polishing agent" removing turbidity and other remaining bacterial contaminants. The filter utilized local materials widely available across Trinidad and Tobago which was inexpensive enough to discard after use, thus eliminating backwashing. The coconut media used for filtration included significant absorption capabilities improving the odour and colour for the treated river water. The filter medium (coconut husk) was only changed once every four to five months with bacteriological removals sufficient to reach potable water standards. Continuous testing of the coconut fibre husk filter was carried out and the accumulated data showed that, for a single pass mode, concentrations of the photochemical dyes ranging from 0.5 to $3.0 \mathrm{mg} / \mathrm{L}$ achieved removal rates of $99.99 \%$ producing effluent water quality recommended by the WHO (World Health Organization) International Drinking Water Standards [34].

\section{Conclusions}

Photosensitisation reactions form the basis for many photobiological effects. The prototype solar photoreactor operated and performed efficiently for the photodegradation of coliforms found in the Maracas-St. Joseph River water. The various photochemical methods of water treatment utilises solar energy as the primary driver of disinfection. Indirect photodegradation or classical sensitized photolysis with its singlet oxygen mechanism may be active towards other toxic compounds with which they can form energy absorbing complexes. Some dissolved and suspended species can produce highly reactive oxidising free radicals such as the hydroxyl radical, when produced in high concentrations indiscriminately destroy and act as a scavenger on impurities in water. The microbiological processes occurring in the photoreactor are responsible for transforming the substrates (microbial pollutants) which is consumed during the photochemical reaction and the photoinduced processes (either direct or sensitized) lead to the degradation of faecal coliform bacteria with a concomitant reduction in the bacteria's activity. It would be feasible to increase the capacity and productivity of the reactor. Under field conditions it would be essential to limit the disinfection process to that part of the day with sufficiently bright sunlight. An alternating "on" and "off" operations could be carried out by installing a timer and photocell sensor. The photoreactors' higher cost may be justified for large-scale installations. Further investigations are underway to test potential photosensitisers such as rose bengal and the photogegradation of other environmentally relevant pathogenic indicators such as E. coli and Enterococcus. The advanced oxidation processes driven by solar energy have been shown to be an efficient method in removing faecal bacteria from river water. The prototype solar photoreactor operated and performed efficiently for the photodegradation of faecal coliforms found in the river and the photodynamic processes exerted by both dyes can be used for water remediation and pollutant remediation. The various photochemical methods of water treatment utilising solar energy as the primary driver of disinfection in addition to the application coconut husk fibre filtration increased the decomposition rates of the bacteria and have been shown to be an efficient and low-cost option for water disinfection in the Caribbean. The quality of the effluent from the two-stage treatment process of solar photochemical disinfection followed by coconut-husk fibre filtration represents a reasonable good quality for residents in remote villages across Trinidad and Tobago.

\section{Conflict of Interests}

The authors certify that there is no conflict of interests with any financial organization or research institutions regarding the material discussed in the paper.

\section{Acknowledgments}

Special gratitude is extended to Key-North Engineering for funding this research project. Appreciation is expressed to DESALCOTT (Desalination Company of Trinidad \& Tobago) and their engineering manager Mr. Tawari TotaMaharaj for partially supporting the project and for his technical and financial assistance. The authors acknowledge Dr. Krishpersad Manohar from the Department of Mechanical Engineering, University of the West Indies, for supporting their research. They would like to extend appreciation to CARIRI (Caribbean Industrial Research Institute), and the District Medical Officer for the East-West Corridor, Trinidad (Dr. Vidhya Gyan Tota-Maharaj) for their kind assistance, advice, and support regarding the microbiological analysis.

\section{References}

[1] D. Bahnemann, R. Dillert, and R. Goslich, "Solar water treatment: principles and reactors," Water Science and Technology, vol. 35, no. 4, pp. 137-148, 1997.

[2] J. Calkins, J. D. Buckles, and J. R. Moeller, "The role of solar ultraviolet radiation in "natural" water purification," Photochemistry and Photobiology, vol. 24, no. 1, pp. 49-57, 1976.

[3] A. J. Acher and I. Rosenthal, "Dye-sensitized-photo-oxidation-a new approach to the treatment of organic matter in sewage effluents," Water Research, vol. 11, no. 7, pp. 557-562, 1977.

[4] A. Acra, M. JurdI, H. Mu'allem, Y. Karahagopian, and R. Raffoul, "Solar ultraviolet radiation: assessment and application for drinking-water disinfection," Report for International Development Research Centre, International Development Research Centre, Ottawa, Canada, 1987.

[5] M. Wegelin, S. Canonica, K. Mechsner, T. Fleischmann, F. Pesaro, and A. Metzler, "Solar water disinfection: scope of the process and analysis of radiation experiments," Journal of Water Supply, vol. 43, no. 3, pp. 154-169, 1994.

[6] A. T. Cooper, D. Y. Goswami, and S. S. Block, "Simultaneous detoxification and disinfection of water by solar photocatalytic treatment," in Proceedings of the ASME International Solar Energy Conference, pp. 277-282, Washington, DC, USA, April 1997.

[7] T. Oppenlander, Photochemical Purification of Water and Air: Advanced Oxidation Processes (AOPs)_Principles, Reaction Mechanisms, Reactor Concepts, Wiley-VCH, Weinheim, Germany, 2002. 
[8] D. Ramlakhan, Solar photocatalytic detoxification of industrial wastewater in Trinidad and Tobago [Ph.D. thesis], University of the West Indies, St. Augustine, Trinidad and Tobago, 2010.

[9] A. Acra, Z. RaffouL, and Y. Karahagopian, Solar Disinfection of Drinking Water and Oral Rehydration Solutions: Guidelines for Household Application in Developing Countries, UNICEF, New York, NY, USA, 1984.

[10] J. Blanco, S. Malato, and C. Richter, "Solar chemistry technology," in Proceedings of the Conference: Solar Thermal Test Facilities, pp. 145-164, CIEMAT, Madrid, Spain.

[11] A. T. Cooper, D. Y. Goswami, and S. S. Block, "Solar photochemical detoxification and disinfection for water treatment in tropical developing countries," Journal of Advanced Oxidation Technologies, vol. 3, no. 2, pp. 151-154, 1998.

[12] X. Li, P. Fitzgerald, and L. Bowen, "Sensitized photodegradation of chlorophenols in a continuous flow reactor system," Water Science and Technology, vol. 26, no. 1-2, pp. 367-376, 1992.

[13] P. G. Tratnyek, M. S. Elovitz, and P. Colverson, "Photoeffects of textile dye wastewaters: sensitization of singlet oxygen formation, oxidation of phenols and toxicity to bacteria," Environmental Toxicology and Chemistry, vol. 13, no. 1, pp. 2733, 1994.

[14] J. McCambridge and T. A. McMeekin, "Effect of solar radiation and predacious microorganisms on survival of faecal and other bacteria," Journal of Applied and Environmental Microbiology, vol. 41, no. 5, pp. 1083-1087, 1981.

[15] K. G. McGuigan, T. M. Joyce, and R. M. Conroy, "Solar disinfection: use of sunlight to decontaminate drinking water in developing countries," Journal of Medical Microbiology, vol. 48, no. 9, pp. 785-787, 1999.

[16] M. G. Nickelsen, W. J. Cooper, K. Lin, C. N. Kurucz, and T. D. Waite, "High energy electron beam generation of oxidants for the treatment of benzene and toluene in the presence of radical scavengers," Water Research, vol. 28, no. 5, pp. 1227-1237, 1994.

[17] S. M. Rodríguez, C. Richter, J. B. Gálvez, and M. Vincent, "Photocatalytic degradation of industrial residual waters," Journal of Solar Energy, vol. 56, no. 5, pp. 401-410, 1996.

[18] D. Y. Goswami, G. Mathur, and C. K. Jotshi, "Methodology of design of non-concentrating solar detoxification systems," in Proceedings of the Engineering Systems Design and Analysis, vol. 3, pp. 117-121, American Society of Mechanical Engineers (ASME), 1994.

[19] S. Malato, J. Blanco, C. Richter, D. Curcó, and J. Giménez, "Low-concentration CPC collectors for photocatalytic water detoxification: comparison with a medium concentrating solar collector," Water Science and Technology, vol. 35, no. 4, pp. 157164, 1997.

[20] A. J. Acher, E. Fischer, and Y. Manor, "Design and operation of photochemical disinfection plants for domestic effluents," in Proceedings of the IAQW International Specialized Conference on Design and Operation of Small Wastewater Treatment Plants, pp. 351-358, Trondhiem, Trondheim, Norway, 1993.

[21] Q. Huang, W. L. Fu, B. Chen, J. F. Huang, X. Zhang, and Q. Xue, "Inactivation of dengue virus by methylene blue/narrow bandwidth light system," Journal of Photochemistry and Photobiology, vol. 77, no. 1-3, pp. 39-43, 2004.

[22] T. M. Joyce, K. G. McGuigan, M. Elmore-Meegan, and R. M. Conroy, "Inactivation of fecal bacteria in drinking water by solar heating," Applied and Environmental Microbiology, vol. 62, no. 2, pp. 399-402, 1996.
[23] F. M. Salih, "Enhancement of solar inactivation of Escherichia coli by titanium dioxide photocatalytic oxidation," Journal of Applied Microbiology, vol. 92, no. 5, pp. 920-926, 2002.

[24] H. Zhou and D. W. Smith, "Advanced technologies in water and wastewater treatment," Journal of Environmental Engineering and Science, vol. 1, no. 4, pp. 247-264, 2002.

[25] R. C. Souza, J. C. Junqueira, R. D. Rossoni, C. A. Pereira, E. Munin, and A. O. C. Jorge, "Comparison of the photodynamic fungicidal efficacy of methylene blue, toluidine blue, malachite green and low-power laser irradiation alone against Candida albicans," Lasers in Medical Science, vol. 25, no. 3, pp. 385-389, 2010.

[26] E. E. Geldreich, H. F. Clark, C. B. Huff, and L. C. Best, "Feacal coliform-organism medium for the membrane filter technique," Journal of the American Water Works Association, vol. 57, article 208, 1965.

[27] B. L. Green, W. Litsky, and K. J. Sladek, "Evaluation of membrane filter methods for enumeration of faecal coliforms from marine water," Marine Environmental Research, vol. 3, no. 4, pp. 267-276, 1980.

[28] F. J. Beltran, G. Ovejero, and B. Acedo, "Oxidation of atrazine in water by ultraviolet radiation combined with hydrogen peroxide," Water Research, vol. 27, no. 6, pp. 1013-1021, 1993.

[29] D. Bockelmann, D. Weichgrebe, R. Goslich, and D. Bahnemann, "Concentrating versus non-concentrating reactors for solar water detoxification," Solar Energy Materials and Solar Cells, vol. 38, no. 1-4, pp. 441-451, 1995.

[30] J. C. Crittenden, S. Hu, D. W. Hand, and S. A. Green, "A kinetic model for $\mathrm{H}_{2} \mathrm{O}_{2} / \mathrm{UV}$ process in a completely mixed batch reactor," Water Research, vol. 33, no. 10, pp. 2315-2328, 1999.

[31] T. Nyokong and V. Ahsen, Photosensitizers in Medicine, Environment and Security, Springer, London, UK, 2012.

[32] H. Xu, W. J. Cooper, J. Jung, and W. Song, "Photosensitized degradation of amoxicillin in natural organic matter isolate solutions," Water Research, vol. 45, no. 2, pp. 632-638, 2011.

[33] G. Jori, M. Magaraggia, C. Fabris et al., "Photodynamic inactivation of microbial pathogens: disinfection of water and prevention of water-borne diseases," Journal of Environmental Pathology, Toxicology and Oncology, vol. 30, no. 3, pp. 261-271, 2011.

[34] World Health Organisation (WHO), Guidelines for DrinkingWater Quality, vol. 1, World Health Organisation, Geneva, Switzerland, 3rd edition, 2006. 

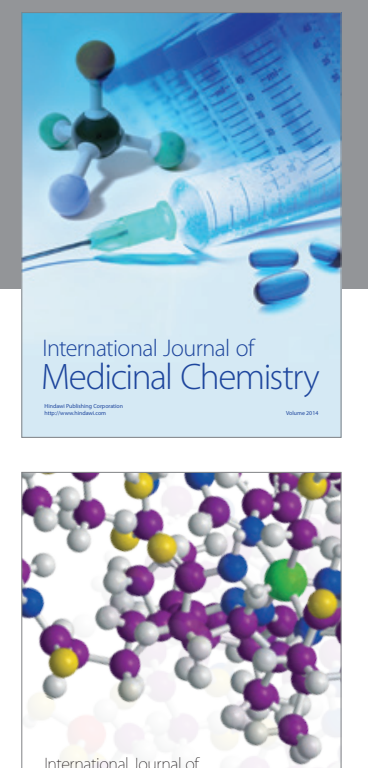

\section{Carbohydrate} Chemistry

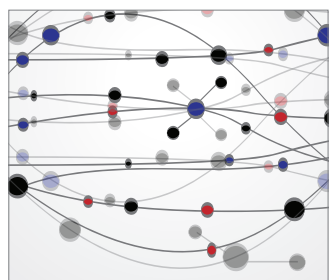

The Scientific World Journal
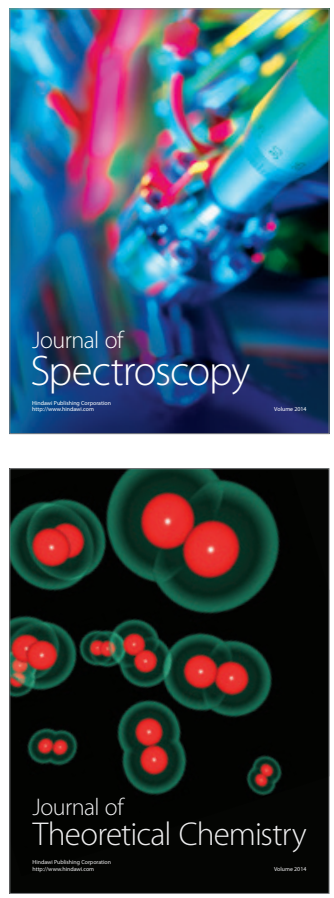
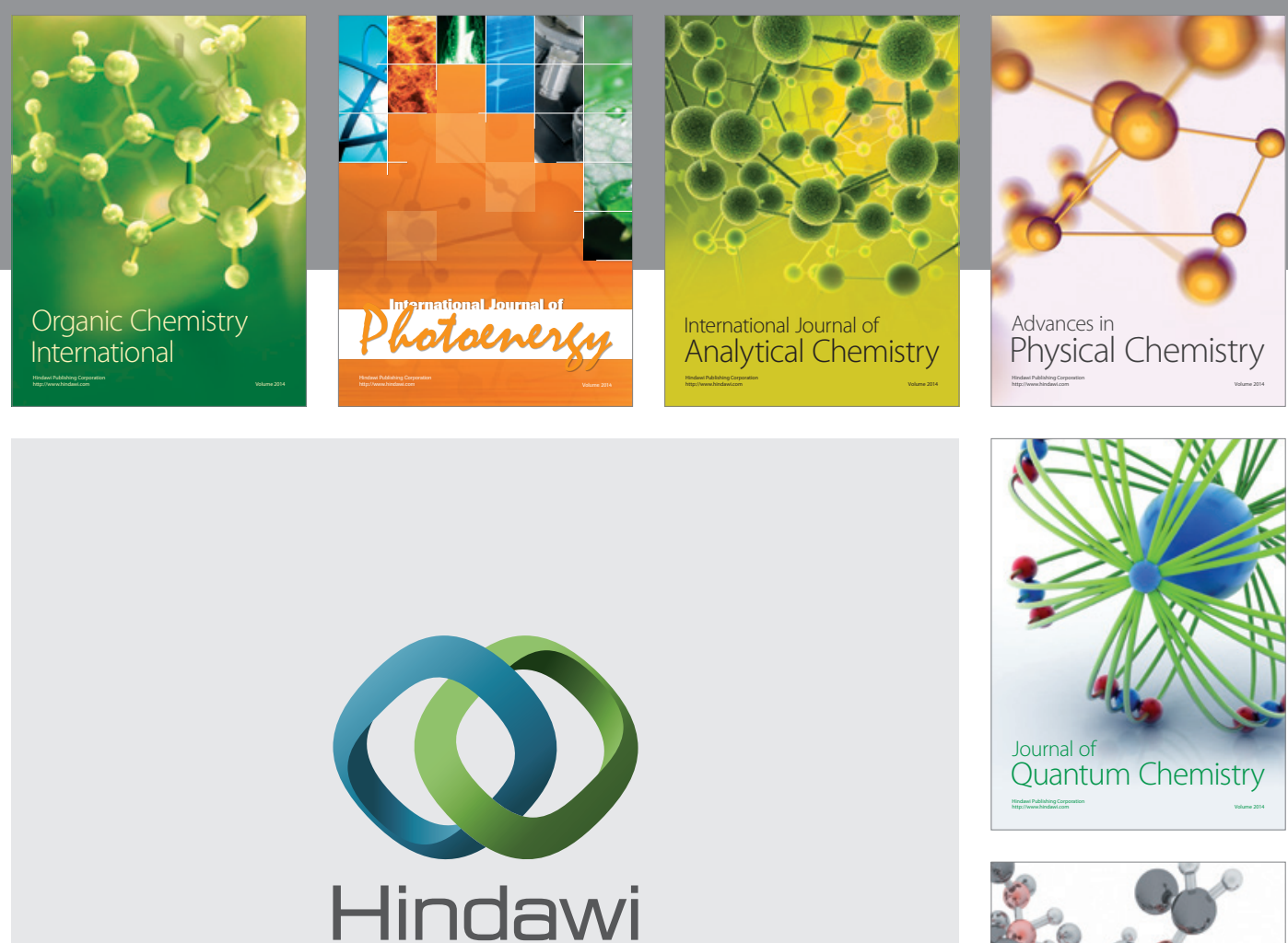

Submit your manuscripts at

http://www.hindawi.com

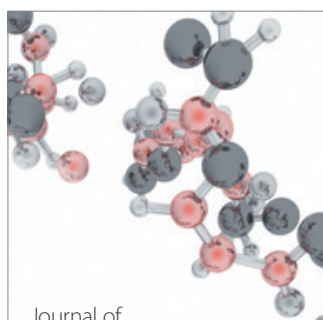

Analytical Methods

in Chemistry

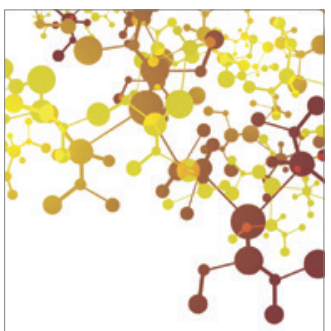

Journal of

Applied Chemistry

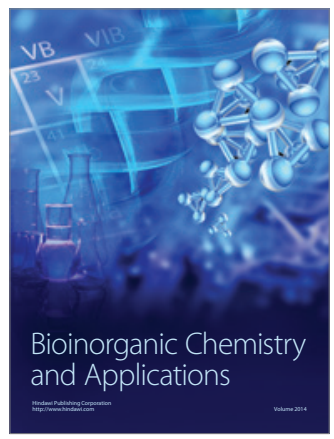

Inorganic Chemistry
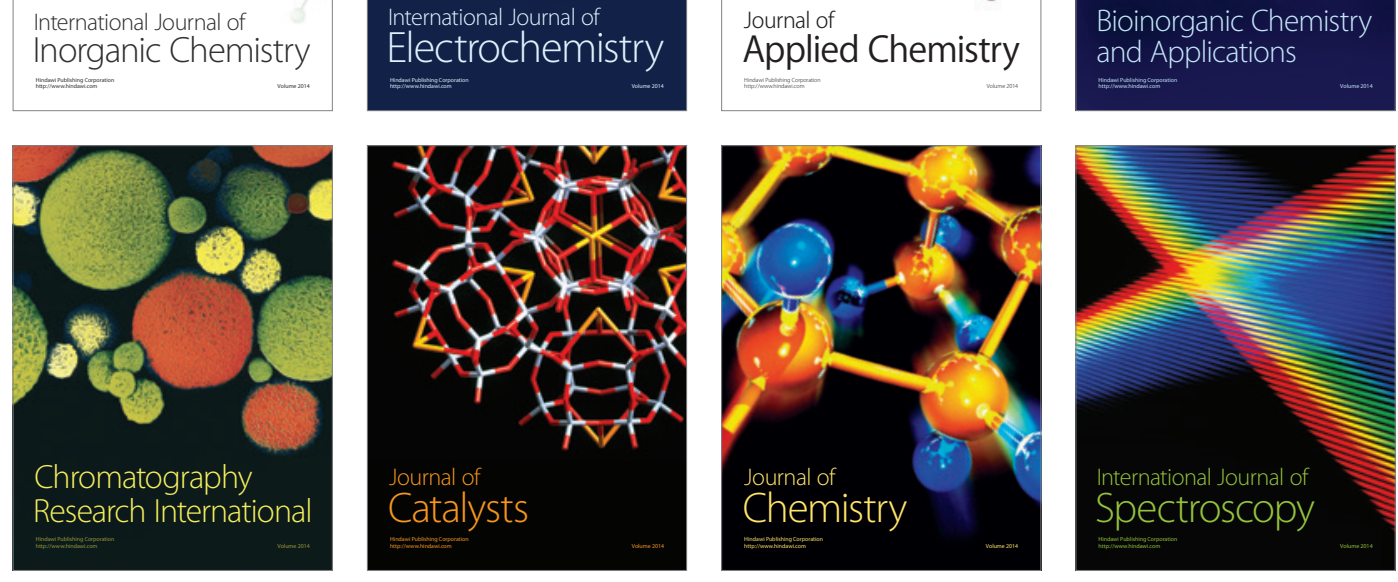